\title{
Application of the dyadic data analysis in behavioral medicine research: marital satisfaction and anxiety in infertile couples

Saman Maroufizadeh ${ }^{1,2}$, Mostafa Hosseini ${ }^{2 *}$, Abbas Rahimi Foroushani ${ }^{2}$, Reza Omani-Samani ${ }^{1 *}$ and Payam Amini ${ }^{1}$

\begin{abstract}
Background: Dyadic data analysis (DDA) is increasingly being used to better understand, analyze and model intra- and inter-personal mechanisms of health in various types of dyads such as husband-wife, caregiver-patient, doctor-patient, and parent-child. A key strength of the DDA is its flexibility to take the nonindependence available in the dyads into account. In this article, we illustrate the value of using DDA to examine how anxiety is associated with marital satisfaction in infertile couples.
\end{abstract}

Methods: This cross-sectional study included 141 infertile couples from a referral infertility clinic in Tehran, Iran between February and May 2017. Anxiety and marital satisfaction were measured by the anxiety subscale of the Hospital Anxiety and Depression Scale and 10-Item ENRICH Marital Satisfaction Scale, respectively. We apply and compare tree different dyadic models to explore the effect of anxiety on marital satisfaction, including the Actor-Partner Interdependence Model (APIM), Mutual Influence Model (MIM), and Common Fate Model (CFM).

Results: This study demonstrated a practical application of the dyadic models. These dyadic models provide results that appear to give different interpretations of the data. The APIM analysis revealed that both men's and women's anxiety excreted an actor effect on their own marital satisfaction. In addition, women's anxiety exerted a significant partner effect on their husbands' marital satisfaction. In MIM analysis, in addition to significant actor effects of anxiety on marital satisfaction, women's reports of marital satisfaction significantly predicted men's marital satisfaction. The CFM analysis revealed that higher couple anxiety scores predicted lower couple marital satisfaction scores.

Conclusion: In sum, the study highlights the usefulness of DDA to explore and test the phenomena with inherently dyadic nature. With regard to our empirical data, the findings confirmed that marital satisfaction was influenced by anxiety in infertile couples at both individual and dyadic level; thus, interventions to improve marital satisfaction should include both men and women. In addition, future studies should consider using DDA when dyadic data are available.

Keywords: Dyadic data analysis, Dyad, Anxiety, Marital satisfaction, Infertility

\section{Background}

Infertility is an ongoing public health problem and is estimated to affect $9 \%$ of reproductive-aged couples worldwide [1]. Besides being a medical condition in itself, infertility is a social condition that can lead to considerable social and psychological distress [2, 3]. Among psychological distress, anxiety is one of the most frequent

\footnotetext{
* Correspondence: mhossein110@yahoo.com; samani@royaninstitute.org ${ }^{2}$ Department of Epidemiology and Biostatistics, School of Public Health, Tehran University of Medical Sciences, Tehran, Iran

'Department of Epidemiology and Reproductive Health, Reproductive Epidemiology Research Center, Royan Institute for Reproductive Biomedicine, ACECR, Tehran, Iran
}

(c) The Author(s). 2018 Open Access This article is distributed under the terms of the Creative Commons Attribution 4.0 International License (http://creativecommons.org/licenses/by/4.0/), which permits unrestricted use, distribution, and reproduction in any medium, provided you give appropriate credit to the original author(s) and the source, provide a link to the Creative Commons license, and indicate if changes were made. The Creative Commons Public Domain Dedication waiver (http://creativecommons.org/publicdomain/zero/1.0/) applies to the data made available in this article, unless otherwise stated. two studies conducted in Iran, the prevalence of anxiety and genialized anxiety disorder were $49.6 \%$ and $33.0 \%$, respectively, which are considerably higher than what was reported in general population $[4,5]$. One the other hand, it has been frequently reported that infertility and its treatments can cause a negative effect on one's marital satisfaction [6,7]. Also, some previous studies have found that subclinicals anxiety symptoms was negatively associated with marital satisfaction [8]. Since infertility is a shared condition within the couple [9], considering 
both members of the couple in the analysis of their relationships is necessary.

On the other hand, one of the basic assumptions underlying statistical analysis is the independence of observations. However, the dyadic designs (e.g., research on man-woman dyads and caregiver-patient dyads) create observations that are not independent which make the conventional statistical methods as inappropriate analysis tools [10]. This type of design is usually applicable when researchers want to understand relationship processes between two people. Some of these processes are inherently dyadic processes, and one of the special characteristics of these processes is dyadic nonindependence. Conceptually, dyadic nonindependence is defined as "if the two scores from the two members of the dyad are non-independent, then those two scores are more similar to (or different from) one another than are two scores from two people who are not members of the same dyad" [10]. Dyadic nonindependence occurs in a variety of contexts that involve two people, such as relationship processes studies in husband-wife, doctor-patient, caregiver-patient, parentchild, siblings and friends. In these conditions, statistical analytical techniques that take non-independence into account is required. To address this issue, Kenny et al. [10] developed three important classes of dyadic models: the Actor-Partner Interdependence Model (APIM), Mutual Influence Model (MIM), and Common Fate Model (CFM). A detailed description of these models is presented in the Methods section.

Most of the studies with inherently dyadic nature in the infertility context and other behavioral medicine have been analyzed using individual as the unit of analysis rather than dyads. Although valuable, these studies fail to consider the dyadic non-independency of the data resulting in biased estimates of associations [11]. However, in the last two decades, a great number of researchers have started to develop dyadic data analysis (DDA) techniques that consider dyadic nonindependence as a source of information rather than attempt to control for it $[12,13]$. In the context of infertility, APIM framework is by far the most widely used model to examine many relationship processes, such as effect of severe depressive symptoms on infertility-related distress [14], attachment patterns on perceived infertility stress [15], and the role of attachment anxiety and attachment avoidance on the psychosocial well-being [16]. Although, the DDA are being used more and more in a variety of researches as a framework for investigating dyadic processes [17-19], many of researchers still require more information on how to analyze the data in a way that optimizes its value [13]. Thus, the aim of this article is twofold. First, we explain how DDA can aid our understanding of dyadic nature of phenomena in medical research. Second, we used three different dyadic models (i.e. APIM, MIM, and CFM) to examine how anxiety is associated with marital satisfaction in infertile couples. In this study, we examine the following research hypothesis:

APIM analysis: (1) One's level of anxiety is associated with his/her own level of marital satisfaction (actor effects); (2) One's level of anxiety is associated with his/ her spouse's level of marital satisfaction (partner effects); (3) There is a significant difference between male and female actor effects of anxiety on marital satisfaction; (4) There is a significant difference between male and female partner effects of anxiety on marital satisfaction. MIM analysis: (5) There is a dyadic feedback effect between males and females' marital satisfaction; (6) There is a significant difference between male and female dyadic feedback effects of marital satisfaction. CFM analysis: (7) Couple's anxiety is associated with couple's marital satisfaction.

\section{Methods \\ Participants and study design}

This was a cross-sectional study of a sample of infertile couples seeking infertility treatment from Tehran, Iran between February and May 2017. Couples who met the following criteria were invited to participate in this study: experiencing infertility problems; age over 18 years; ability to read and write in Persian. Infertility is defined as "the failure to achieve a clinical pregnancy after 12 months or more of regular unprotected sexual intercourse" [20]. Couples were instructed to fill out the instruments separately from each other in a quiet place. It took about $5 \mathrm{~min}$ to complete the questionnaires. In total, 141 infertile couples agreed to participate and filled out the instruments completely (response rate: $82.3 \%$ ).

\section{Measures \\ Marital satisfaction}

Marital satisfaction was measured by the 10-Item ENRICH Marital Satisfaction Scale (EMS Scale) [21]. Respondents rate items on a 5-point Likert-type scale ranging from 1 (strongly disagree) to 5 (strongly agree). After recoding the negative items, scores are summed to yield a total EMS Scale score ranging from 10 to 50, with higher scores indicating greater levels of marital satisfaction. For this study, the Cronbach's alpha coefficient of the EMS Scale for males and females were 0.752 and 0.790 , respectively.

\section{Anxiety}

Anxiety was measured by the anxiety subscale of the Hospital Anxiety and Depression Scale (HADS). The HADS is a widely used self-report instrument consisting 14 items designed to measure both anxiety (HADS-A) and depression (HADS-D) [22]. Items are rated on a 
4-point Likert scale, ranging from 0 (no symptoms) to 3 (severe symptoms). Both subscales scores range from 0 to 21 , with higher scores indicating greater levels of anxiety and depression. The Persian version of HADS has been validated [23] and widely used among infertile patients $[4,23]$. For this study, the Cronbach's alpha coefficients of the HADS-A for males and females were 0.841 and 0.865 , respectively.

\section{Statistical analysis}

As mentioned above, there are three main dyadic models for the analysis of the dyadic design. In this section, we describe these models in terms of the simplest scenario, one in which there is one independent variable $(\mathrm{X})$ and one dependent variable $(\mathrm{Y})$ for each member of a dyad, or four variables altogether.

\section{APIM framework}

The APIM is the most widely used model in dyadic research which developed by Kenny [10, 13]. This model is useful in determining intrapersonal effect (actor effect) and interpersonal effect (partner effect). Figure 1 depicts the basic APIM for Member 1 and Member 2. The path from the person's $\mathrm{X}$ to that person's $\mathrm{Y}$ is called actor effect and the path to the other person's $Y$ is called partner effect. In other words, the actor effect measures the degree to which a person's outcome is influenced by his/ her own characteristics, whereas the partner effect measures the degree to which a person's outcome is influenced by his or her partner's characteristics. As an example, consider the effects of anxiety on marital satisfaction in men-women dyads with infertility problem. It may be that one's anxiety influences both her/his own and spouse's marital satisfaction. This model has two actor effects $a_{1}$ and $a_{2}$ (horizontal arrows), and two partner effects $\mathrm{p}_{12}$ and $\mathrm{p}_{21}$ (diagonal arrows). In

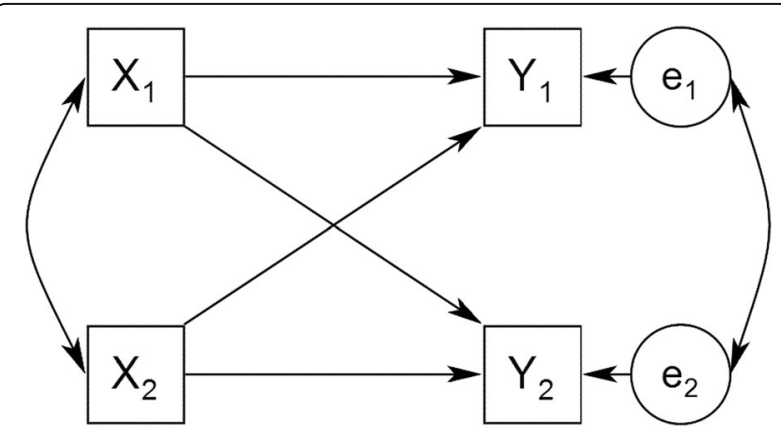

Fig. 1 The Actor-Partner Interdependence Model (APIM). Note. $X_{1}$ and $X_{2}$ are predictor variables for person 1 and person $2, Y_{1}$ and $Y_{2}$ are their respective outcome variables, and $e_{1}$ and $e_{2}$ are the corresponding error terms. The effect of a person's $X$ on his or her own $Y$ is an actor effect. The effect of a person's $X$ on the partner's $Y$ is a partner effect [11] addition, there are also two major correlations in the APIM. The two $\mathrm{X}$ variables might be correlated, indicating probably compositional effect. The second correlation is the residual nonindependence in the $\mathrm{Y}$ variables, which represents the nonindependence not explained by the APIM.

Multilevel modeling (MLM) and structural equation modeling (SEM) are the dominant methods to estimate the APIM. As recommended in the literature [10, 24], SEM approach is the simplest method for estimating the APIM in case of distinguishable dyads. Furthermore, in this study, to examine whether the actor effects as well as the partner effect differed between men and women, we constrained these two coefficients to be equal and compared the chi-square statistics for the constrained and unconstrained (saturated) models.

\section{MIM framework}

Like the APIM framework, the MIM is a model of interdependence because it models interpersonal effects (see Fig. 2). However, in the MIM framework, both persons' outcomes directly influence one another (i.e. there is a dyadic feedback). Contrary to the APIM, the other cause of each person's $\mathrm{Y}$ variable is not the partner's $\mathrm{X}$ variable, but the partner's $Y$ variable. As one example, the MIM framework is useful to investigate marital satisfaction because of the reciprocity of this concept in relationship researches $[25,26]$. The details of the method of estimation for MIM are discussed in Ref [10, 27].

\section{CFM framework}

The third source that may produce nonindependence in dyads is common fate. Common fate occurs when both dyad members are affected by the same factor, such as environmental, cultural, or structural elements, or shared

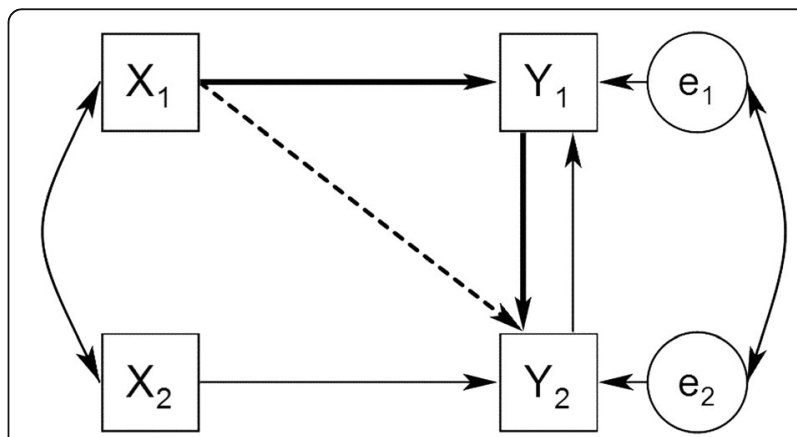

Fig. 2 The Mutual Influence Model (MIM). Note. $X_{1}$ and $X_{2}$ are predictor variables for person 1 and person $2, Y_{1}$ and $Y_{2}$ are their respective outcome variables, and $e_{1}$ and $e_{2}$ are the corresponding error terms. Each person's outcome $(Y)$ influences the other's outcome. The effect of each actor's independent variable on the partner's outcome $(Y)$ is mediated by the actor's own outcome (see bolded arrows). The dashed line represents the indirect effect of the actor on the partner [11] 
experiences [28]. For example, a parent and a child may be similar in some respect because they share a certain gene [29]. In the CFM, the covariation between dyad members' scores is assumed to be due to some unmeasured factor that impacts both dyad members. In other words, the dyad members do not impact each other, but, rather, the same external force impacts both. As depicted in Fig. 3, in the CFM, the causal effect from X to Y occurs between latent variables. These latent variables are assumed to be variables that affect both members of the dyad. The details of the CFM and discussion of variables useful for this model are presented in in Ref. [28, 30-32].

\section{Statistical software and model fit}

We conducted structural equation modeling (SEM) using maximum likelihood estimation to test the models. Overall model fit was evaluated using multiple fit indices, as suggested in the literature. Specifically, five goodness-of-fit indices were used, including chi-square/ degree of freedom $\left(x^{2} / \mathrm{df}\right)$, Tucker-Lewis Index (TLI), comparative fit index (CFI), root mean square error of approximation (RMSEA), and standardized root mean square residual (SRMR). Values of $x^{2} / \mathrm{df}<2$, TLI and CFI $>0.95$, and RMSEA and SRMR $<0.08$ are indicative of a good fit with the data [33-36].

All preliminary analyses were done with IBM SPSS Statistics for Windows, Version 22.0 (IBM Crop., Armonk, NY, USA) and DDA was done with Mplus software version 6.12 (Muthén \& Muthén, Los Angeles, CA, USA).

\section{Results}

\section{Characteristics of the infertile couples}

Demographic and fertility characteristics of the infertile couples are outlined in Table 1. The husband, on

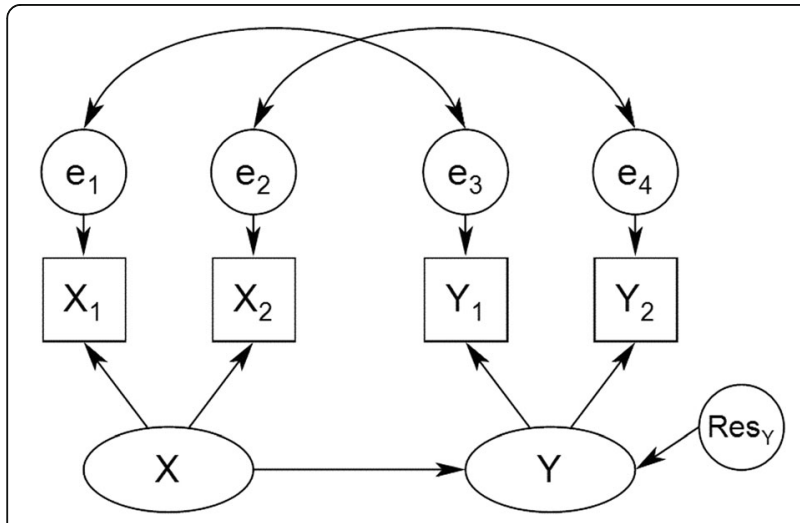

Fig. 3 The Common Fate Model (CFM). Note. $X_{1}, X_{2}, Y_{1}$, and $Y_{2}$ denote manifest variables measured in person 1 and person $2 ; X$ and $Y$ indicate latent variables. The latent predictor variable $(X)$ influences the latent outcome variable $(Y)$. Residuals (e.g., $e_{1}$ and $e_{3}$ ) are correlated within person. Resy is the residual on the latent outcome variable [11] average, were 5.10 years older than their wives $\left(\mathrm{t}{ }_{(140)}=\right.$ $12.88, P<0.001)$, but they had a similar level of education as their wives $\left(X_{(1)}^{2}=2.56, P=0.109\right)$. The average of infertility duration was $4.85 \pm 3.76$ years. The causes of infertility were as follows: male factor (36.2\%), female factor (21.3\%), both (19.1\%), and unexplained (23.4\%). The majority of the couples had primary infertility (72.3\%), and no history of abortion (76.6\%) and half of them experience at least one failure in previous infertility treatments.

\section{Preliminary analyses}

Means, SDs, and correlations for study variables are given in Table 2. There was no significant difference between men's and women's marital satisfaction $\left(\mathrm{t}{ }_{(140)}=\right.$ $0.09, P=0.925)$. Women, however, reported higher anxiety than men $\left(\mathrm{t}_{(140)}=3.39, P<0.001\right)$. As seen in Table 2, men's anxiety was correlated with their own as well as their wives' marital satisfaction. Women's anxiety was also correlated with their own as well as their husbands' marital satisfaction. In addition, the within-dyad correlations between marital satisfaction and anxiety were direct and significant, indicating that if one partner was satisfied with their martial satisfaction and had high level of anxiety, the other one was also.

\section{Dyadic data analysis APIM analyses}

The results of the basic APIM (Model 1) and three variations of the model (Model 2, Model3, and Model 4) are presented in Table 3. With regard to actor effects in Model 1, men as well as women who were highly anxious were less satisfied with their marital relationship $(\mathrm{b}=-0.457, P<0.001 ; \mathrm{b}=-0.445, P<0.001$, respectively). In other words, after adjusting for partner effects, each 1-point increase in one's own anxiety score was associated with a 0.46 - and 0.45-point decrease in one's own marital satisfaction among men and women, respectively. With regard to partner effects, men with highly anxious wives reported lower level of marital satisfaction $(b=-0.254, P=0.031)$, whereas the partner effect of men's anxiety on women's marital satisfaction was not statistically significant $(b=-0.150, P=0.235)$. In other words, after adjusting for the actor effect, a unit increase of the women's anxiety was associated with a 0.25 -point decrease in their husbands' marital satisfaction. The basic APIM is fully saturated, thus goodness-of-fit indices were not interpreted.

In order to further examine these effects, several equality constraint tests were conducted to compare actor and/or partner effects between men and women by the examination of the chi-square difference test. Constraining the actor effects to be equal (see Model 2 in Table 3) did not significantly worsen the model fit 
Table 1 Demographic and fertility characteristics of the infertile couples ( $n=141$ couples)

\begin{tabular}{|c|c|c|c|c|}
\hline & Men & Women & Test statistic & $P$ \\
\hline Age (years) & $34.92 \pm 6.35$ & $29.82 \pm 6.00$ & $t_{(140)}=12.88$ & $<0.001$ \\
\hline Educational level & & & $x_{(1)}^{2}=2.56$ & 0.109 \\
\hline Non-academic & $96(68.1)$ & $85(60.3)$ & & \\
\hline Academic & $45(31.9)$ & $56(39.7)$ & & \\
\hline Duration of marriage (years) & $7.37 \pm 4.40$ & - & & \\
\hline Duration of infertility (years) & $4.85 \pm 3.76$ & - & & \\
\hline \multicolumn{5}{|l|}{ Cause of infertility } \\
\hline Male factor & $51(36.2)$ & - & & \\
\hline Female factor & $30(21.3)$ & - & & \\
\hline Both & $27(19.1)$ & - & & \\
\hline Unexplained & $33(23.4)$ & - & & \\
\hline \multicolumn{5}{|l|}{ History of ART treatment failure } \\
\hline No (First treatment) & $71(50.4)$ & - & & \\
\hline Yes & $70(49.6)$ & - & & \\
\hline \multicolumn{5}{|l|}{ History of abortion } \\
\hline No & $108(76.6)$ & - & & \\
\hline Yes & $33(23.4)$ & - & & \\
\hline \multicolumn{5}{|l|}{ Type of infertility } \\
\hline Primary & $102(72.3)$ & - & & \\
\hline Secondary & $39(27.7)$ & - & & \\
\hline
\end{tabular}

Values are given as mean \pm SD or $\mathrm{n}(\%)$

ART Assisted Reproductive Technology

$\left(X^{2}{ }_{(1)}=0.004, P=0.947\right)$, showing that the actor effects of anxiety on marital satisfaction did not differ by gender. The other fit indices for this model were excellent $(\mathrm{CFI}=1.000 ; \mathrm{TLI}=1.000 ; \mathrm{RMSEA}<0.001 ;$ and $\mathrm{SRMR}=$ 0.002). In Model 3, we compared the partner effects between men and women. Similar to Model 2, equal partner effects constraint (see Model 3 in Table 3) did not worsen the fit of the model compared to Model 1 $\left(\chi_{(1)}^{2}=0.334, P=0.563\right)$. In addition, the two previous constraints from Models 2 and 3 were assumed in Model 4 which did not lead to a significance change in model fit $\left(\chi_{(2)}^{2}=0.532, P=0.766\right)$.

\section{MIM analyses}

The results of the basic MIM (Model 5) and three variations of the model (Model 6, Model 7, and Model 8) are presented in Table 4. In the Model 5, men's anxiety was significantly negatively related with their own marital satisfaction ( $b=-0.371, P=0.004)$. Likewise, women's anxiety was significantly negatively related with their own martial satisfaction $(b=-0.361, P=0.011)$. Further, women's reports of marital satisfaction significantly predicted men's marital satisfaction $(b=0.570, P=0.024)$, whereas men's marital satisfaction did not predict women's marital satisfaction $(b=0.329, P=0.202)$. The MIM also estimated the indirect effects of husbands' and wives' anxiety on their partners' marital satisfaction. The indirect effect of wives' anxiety on husbands' marital satisfaction was negative and significant $(b=-0.206$, $P=0.020$ ), but indirect effect of husbands' anxiety on wives' marital satisfaction was not statistically significant $(\mathrm{b}=-0.122, P=0.140$ ). Like the basic APIM (Model 5 ),

Table 2 Means, standard deviations, and correlations among study variables ( $n=141$ couples)

\begin{tabular}{lllll}
\hline & Mean (SD) & 1 & 2 & 3 \\
\hline 1 Men marital satisfaction & $39.31(6.56)$ & 1 & & \\
2 Men anxiety & $6.52(4.30)$ & $-0.336^{* * *}$ & 1 & 1 \\
3 Women marital satisfaction & $39.26(6.70)$ & $0.423^{* * *}$ & -0.159 & $-0.316^{* * *}$ \\
4 Women anxiety & $8.09(4.46)$ & $-0.235^{* *}$ & $0.209^{*}$ & 1 \\
\hline
\end{tabular}

$S D$ Standard Deviation

${ }^{*} P<0.05 ;{ }^{* *} P<0.01 ;{ }^{* * *} P<0.001$ 
Table 3 Results of the APIM framework relating anxiety to marital satisfaction among infertile couples

\begin{tabular}{|c|c|c|c|c|c|c|c|c|}
\hline & \multicolumn{2}{|l|}{ Model 1} & \multicolumn{2}{|l|}{ Model 2} & \multicolumn{2}{|l|}{ Model 3} & \multicolumn{2}{|l|}{ Model 4} \\
\hline & Estimate & SE & Estimate & SE & Estimate & SE & Estimate & SE \\
\hline \multicolumn{9}{|l|}{ Actor effects } \\
\hline $\mathrm{A}_{M} \rightarrow \mathrm{MS}_{M}$ & $-.457^{* * *}$ & .122 & $-.451^{* * * a}$ & .083 & $-.485^{* * *}$ & .112 & $-.451^{* * *_{c}}$ & .083 \\
\hline $\mathrm{A}_{\mathrm{W}} \rightarrow \mathrm{MS}_{\mathrm{W}}$ & $-.445^{* * *}$ & .122 & $-.451^{* * *_{a}}$ & .083 & $-.418^{* * *}$ & .113 & $-.451^{* * * c}$ & .083 \\
\hline \multicolumn{9}{|l|}{ Partner effects } \\
\hline $\mathrm{A}_{\mathrm{W}} \rightarrow \mathrm{MS}_{\mathrm{M}}$ & $-.254^{*}$ & .117 & $-.257^{*}$ & .108 & $-.206^{* b}$ & .083 & $-.207^{* d}$ & .083 \\
\hline$A_{M} \rightarrow M S_{W}$ & -.150 & .127 & -.147 & .116 & $-.206^{* b}$ & .083 & $-.207^{* d}$ & .083 \\
\hline \multicolumn{9}{|l|}{ Covariances } \\
\hline$A_{M} \leftrightarrow A_{W}$ & $3.988^{*}$ & 1.638 & $3.988^{*}$ & 1.638 & $3.988^{*}$ & 1.638 & $3.988^{*}$ & 1.638 \\
\hline $\operatorname{Res} \mathrm{MS}_{M} \leftrightarrow \operatorname{Res} \mathrm{MS}_{W}$ & $13.997^{* * *}$ & 3.421 & $13.999^{* * *}$ & 3.422 & $14.040^{* * *}$ & 3.429 & $13.976^{* * *}$ & 3.425 \\
\hline \multicolumn{9}{|l|}{ Model fit } \\
\hline$x^{2}$ & - & & .004 & & .334 & & .532 & \\
\hline$d f$ & - & & 1 & & 1 & & 2 & \\
\hline$P$ & - & & .947 & & .563 & & .766 & \\
\hline$x^{2} / d f$ & - & & .004 & & .334 & & .266 & \\
\hline $\mathrm{CFI}$ & - & & 1.000 & & 1.000 & & 1.000 & \\
\hline TLI & - & & 1.000 & & 1.000 & & 1.000 & \\
\hline RMSEA & - & & $<.001$ & & $<.001$ & & $<.001$ & \\
\hline SRMR & - & & .002 & & .012 & & .023 & \\
\hline
\end{tabular}

Res $M S_{M}$ and Res $M S_{W}$ are residual terms of $M S_{M}$ and $M S_{W}$, respectively

Note. $n=141$. SE Standard Error, CFI Comparative Fit Index, TLI Tucker-Lewis Index, RMSEA Root Mean Square Error of Approximation, SRMR Standardized Root

Mean Square Residual

$A_{M}$ Men's Anxiety, $A_{W}$ Women's Anxiety, $M S_{M}$ Men's Marital Satisfaction, $M S_{W}$ Women's Marital Satisfaction

${ }^{*} P<0.05 ;{ }^{* *} P<0.01 ;{ }^{* * *} P<0.001$

abcd These coefficients were constrained to be equal

the basic MIM is also fully saturated. In this framework, we performed several contrasts that were of theoretical importance. Like the Model 2, the first test constrained the actor effects for men and women to be equal (Model 6). This constraint did not lead to significant decrease in model fit $\left(X_{(1)}^{2}=0.004, P=0.947\right)$. The second test constrained the dyadic feedback effects for men and women to be equal (Model 7). This constraint also did not lead to significantly poorer model fit $\left(\chi^{2}{ }_{(1)}=0.514, P=0.473\right)$. In addition, the two previous constraints from Models 6 and 7 were tested in Model 8 simultaneously. These constraints also did not lead to significant decrease in model fit $\left(\mathrm{X}_{(2)}^{2}=0.532, P=0.766\right)$.

\section{CFM analysis}

As mentioned above, the correlations between men and women were medium for marital satisfaction and relatively low for anxiety. Thus, these findings may be taken as supporting the assumption that infertile couples share common variance on these two constructs, particularly for marital satisfaction. In addition, the finding that actor and partner effects between anxiety and marital satisfaction were similar in magnitude and direction justifies the implementation of these dyadic variables in a
CFM framework. To test the model in this framework (Model 9), we set all factor loadings of the two latent variables anxiety and marital satisfaction to 1 . As expected, higher couple anxiety scores predicted lower levels of marital satisfaction $(b=-1.440, P=0.012)$. This model fit the data well: $X_{(1)}^{2}=0.529, P=0.467 ; \mathrm{CFI}=$ 1.000; $\mathrm{TLI}=1.000 ; \mathrm{RMSEA}<0.001 ;$ and $\mathrm{SRMR}=0.017$. The explained variance of marital satisfaction through anxiety was $44.1 \%$ (Table 5).

\section{Discussion}

We used the APIM, MIM, and CFM frameworks to explore the associations among husbands' and wives' assessments of anxiety and marital satisfaction, using data gathered from 141 infertile couples who seek treatments for infertility in Tehran, Iran. The findings from these analyses all show that anxiety is related to marital satisfaction. The interpretation of that relationship, however, would be different depending on which analysis one performed.

Key findings from the APIM analyses were that (a) men's and women's report of their anxiety predicted changes in their marital satisfaction (actor effects). Therefore, the Hypothesis 1 was accepted; (b) men's and 
Table 4 Results of the MIM framework relating anxiety to marital satisfaction among infertile couples

\begin{tabular}{|c|c|c|c|c|c|c|c|c|}
\hline & \multicolumn{2}{|l|}{ Model 5} & \multicolumn{2}{|l|}{ Model 6} & \multicolumn{2}{|l|}{ Model 7} & \multicolumn{2}{|l|}{ Model 8} \\
\hline & Estimate & SE & Estimate & SE & Estimate & SE & Estimate & SE \\
\hline \multicolumn{9}{|l|}{ Actor effects } \\
\hline $\mathrm{A}_{M} \rightarrow \mathrm{MS}_{M}$ & $-.371^{* *}$ & .130 & $-.367^{* * a}$ & .115 & $-.368^{*}$ & .144 & $-.357^{* *} c$ & .115 \\
\hline $\mathrm{A}_{\mathrm{W}} \rightarrow \mathrm{MS}_{\mathrm{W}}$ & $-.361^{*}$ & .143 & $-.367^{* * a}$ & .115 & $-.349^{* *}$ & .127 & $-.357^{* * c}$ & .115 \\
\hline \multicolumn{9}{|l|}{ Dyadic feedback effects } \\
\hline $\mathrm{MS}_{\mathrm{W}} \rightarrow \mathrm{MS}_{\mathrm{M}}$ & $.570^{*}$ & .253 & $.570^{*}$ & .249 & $.454^{* \mathrm{~b}}$ & .190 & $.457^{* d}$ & .188 \\
\hline $\mathrm{MS}_{\mathrm{M}} \rightarrow \mathrm{MS}_{\mathrm{W}}$ & .329 & .258 & .326 & .257 & $.454^{* \mathrm{~b}}$ & .190 & $.457^{* d}$ & .188 \\
\hline \multicolumn{9}{|l|}{ Covariances } \\
\hline$A_{M} \leftrightarrow A_{W}$ & $3.988^{*}$ & 1.638 & $3.988^{*}$ & 1.638 & $3.988^{*}$ & 1.638 & $3.988^{*}$ & 1.638 \\
\hline $\operatorname{Res} \mathrm{MS}_{M} \leftrightarrow \operatorname{Res} \mathrm{MS}_{W}$ & -18.067 & 12.583 & -17.954 & 12.444 & -17.812 & 12.555 & -18.065 & 12.418 \\
\hline \multicolumn{9}{|l|}{ Model fit } \\
\hline$x^{2}$ & - & & .004 & & .514 & & .532 & \\
\hline$d f$ & - & & 1 & & 1 & & 2 & \\
\hline$P$ & & & .947 & & .473 & & .766 & \\
\hline$x^{2} / d f$ & - & & .004 & & .514 & & .266 & \\
\hline $\mathrm{CFI}$ & - & & 1.000 & & 1.000 & & 1.000 & \\
\hline TLI & - & & 1.000 & & 1.000 & & 1.000 & \\
\hline RMSEA & - & & $<.001$ & & $<.001$ & & $<.001$ & \\
\hline SRMR & - & & .002 & & .020 & & .023 & \\
\hline
\end{tabular}

Res $M S_{M}$ and Res $M S_{W}$ are residual terms of $M S_{M}$ and $M S_{W}$, respectively

Note. $n=141$. SE Standard Error, CFI Comparative Fit Index, TLI Tucker-Lewis Index, RMSEA Root Mean Square Error of Approximation, SRMR Standardized Root Mean Square Residual

$A_{M}$ Men's Anxiety, $A_{W}$ Women's Anxiety, $M S_{M}$ Men's Marital Satisfaction, $M S_{W}$ Women's Marital Satisfaction

${ }^{*} P<0.05 ;{ }^{* *} P<0.01 ;{ }^{* * *} P<0.001$

${ }^{\text {abcd }}$ These coefficients were constrained to be equal

women's anxiety was associated with their wife's and husband's marital satisfaction, respectively (partner effect) (based on Model 3 and 4). Therefore, the Hypothesis 2 was accepted; (c) actor effects as well as partner effects of anxiety on marital satisfaction were similar between men and women. Therefore, the Hypotheses 3 and 4 were rejected. The key feature of this APIM analysis which cannot be examined by individual model analytical approach is the explore the interpersonal effects (i.e. partner effects).

Findings of the MIM framework indicated that husbands' and wives' marital satisfaction were considerably reciprocally correlated (thus the Hypothesis 5 was accepted), suggesting feedback, and the magnitude of this association was similar (thus the Hypothesis 6 was rejected). The MIM also can test whether husbands' and wives' anxiety are indirectly related with their partners' marital satisfaction via their own marital satisfaction (i.e., mediation). Based on the MIM findings, the indirect effects of spouses' anxiety on their partners' marital satisfaction imply that marital satisfaction in infertile patients was influenced by not only their own anxiety, but also their spouses' anxiety.
The CFM framework provided a valuable insight with regard to the couple-level process. The key finding from this framework was that anxiety symptoms was related with marital satisfaction at the dyadic level. In other words, higher couple anxiety scores predicted lower couple marital satisfaction. Therefore, the Hypothesis 7 was accepted. In the data, two of the key indicators for selecting CFM as a reasonable model were met. First, the interpartner (dyadic) correlations were greater than 0.2 and 0.4 for anxiety and marital satisfaction scores, respectively, which approximately satisfied the recommendations in the literature $[28,31]$ for variables that are thought to represent dyadic-level variation. Second, the result that actor and partner effects between anxiety and marital satisfaction were same in both direction and strength warrants the use of these variables in a CFM framework. Theoretical and methodological issues regarding the selecting of model are discussed in Ref [31, 37].

Regarding preliminary analysis, women's anxiety was significantly higher than their husbands, indicating that women may be more considerably affected than men by infertility problem. This result is in line with previous research [38, 39]. Consistent with previous studies 
Table 5 Results of the CFM framework relating anxiety to marital satisfaction among infertile couples

\begin{tabular}{lll}
\hline & Model 9 & SE \\
\cline { 2 - 3 } & Estimate & .571 \\
\hline Dyadic level effect & $-1.440^{*}$ & \\
$\mathrm{~A} \rightarrow$ MS & & 2.321 \\
Individual-level effects & $-4.010^{\dagger}$ & 2.382 \\
Res $A_{M} \leftrightarrow$ Res $\mathrm{MS}_{M}$ & -3.388 & \\
Res $A_{W} \leftrightarrow$ Res MS & \\
Model fit & & \\
$X^{2}$ & .529 & \\
df & 1 & \\
$P$ & .467 & \\
$X^{2} / d f$ & .529 & \\
CFI & 1.000 & \\
TLI & 1.000 & \\
RMSEA & $<.001$ & \\
SRMR & .017 & \\
\hline
\end{tabular}

Res $A_{M}$, Res $A_{W}$, Res $M S_{M}$, and Res $M S_{W}$ are residual terms of $A_{M}, A_{W}, M S_{M}$, and $M S_{W}$, respectively

Note. $n=141$. SE Standard Error, CFI Comparative Fit Index, TLI Tucker-Lewis Index, RMSEA Root Mean Square Error of Approximation, SRMR Standardized Root Mean Square Residual

$A_{M}$ Men's Anxiety, $A_{W}$ Women's Anxiety, $M S_{M}$ Men's Marital Satisfaction, $M S_{W}$ Women's Marital Satisfaction

${ }^{*} P<0.05 ;{ }^{\dagger} P<0.1$

[40-42], marital satisfaction was unrelated to gender. This finding is also in line with two previous studies on infertile couples' quality of life, measured by the Fertility Quality of Life (FertiQoL), which found that the FertiQoL-Relational scores did not differ across partners [43, 44]. However, in a study performed among infertile couples in Poland, women's marital satisfaction was lower than their husbands [45].

Of all dyadic data analytic approaches, the APIM framework has been-and is likely to continue to be-favored by researchers. However, when measurements are taken on both members of a dyad, researchers must decide whether the process is best represented as interdependent or common fate. The APIM and MIM would be appropriate dyadic models that represent interdependent processes. In APIM framework, interdependence of the outcome variables is hypothesized to come about because of the predictor variables, whereas in MIM framework, interdependence of the outcome variables may come about because these outcome variables simultaneously affect each other [32]. The CFM is a dyadic model that is useful when both dyad members are affected by the common factor.

The current study offers a number of important contributions to the literature. Researches regarding the relationship between anxiety and marital satisfaction tend to focus on individuals, despite the obviously dyadic nature of marital satisfaction, particularly in the infertility context. Moreover, given the paucity of prior research on couples involved in committed marital relationships and shared health condition like infertility problem, the current research conducted among infertile married couples from a dyadic perspective. The results of this study have potentially important clinical implications. First, confirmation of the significance of the studied relationship at the level of the dyad members (individuals) and at the level of the dyads highlights the necessity of considering both members of the dyad in assessment. Second, therapists working with infertile couples should be aware of the different dyadic effects; therefore, psychological interventions that target an improvement in marital satisfaction should treat the couple as a unit.

Several limitations of the study should be noted. First, this research was carried out only in one infertility clinic and therefore limits the generalizability of our findings. Second, due to the cross-sectional nature of the study design, casual inference between anxiety and marital satisfaction cannot be made. Further studies, particularly longitudinal research, are required to disentangle the complex associations between spouses' anxiety and marital satisfaction, including direction of causality and existence of dyadic feedback over time. Other limitations of this study were relatively small sample size, the lack of control for some important clinical variables (i.e., duration of infertility, cause of infertility, and failure of previous treatment), and the lack of specific infertility stress measures.

\section{Conclusion}

In summary, this study highlights the usefulness of DDA to examine and test the phenomena with inherently dyadic nature. We hope that our paper encourages researchers to learn more about dyadic models and how to apply them within the context of behavioral medicine. With regard to our empirical data, the finding confirmed that marital satisfaction in infertile couples was influenced by anxiety at both individual and dyadic level. In addition, the findings showed that a person's anxiety can impact not only their own but also his/her partner's marital satisfaction; thus, interventions to improve marital satisfaction should include both men and women. Furthermore, since infertility and its treatments are shared couple problem, future studies should consider using DDA when dyadic data are available in the infertility context.

\footnotetext{
Abbreviations

APIM: Actor-partner interdependence model; CFI: Comparative fit index;

CFM: Common fate model; DDA: Dyadic data analysis; EMS Scale: ENRICH Marital Satisfaction Scale; HADS: Hospital anxiety and depression scale; MIM: Mutual influence model; RMSEA: Root mean square error of approximation; SEM: Structural equation modeling; SRMR: Standardized root mean square residual; TLI: Tucker-Lewis Index
} 


\section{Acknowledgements}

We thank the infertile couples who participated in this research and to the Royan Institute, Tehran, Iran for cooperation in data acquisition.

\section{Funding}

This research did not receive any specific grant from any agency in the public, commercial, or not-for-profit sector.

\section{Availability of data and materials}

The datasets used and/or analyzed during the current study available from the corresponding author on reasonable request.

\section{Authors' contributions}

SM and MH: Conception and design; Analysis and interpretation of the data; Drafting of the article. ARF: Conception and design; Drafting of the article. ROS and PA: Conception and design; Collection and assembly of data, Drafting of the article. All authors approved the final version of the article for submission.

\section{Ethics approval and consent to participate}

This study was approved by the Ethics Committee of Tehran University of Medical Sciences, Tehran, Iran, and written informed consent from all infertile couples was obtained.

\section{Consent for publication}

Not applicable.

\section{Competing interests}

The authors declare that they have no competing interests.

\section{Publisher's Note}

Springer Nature remains neutral with regard to jurisdictional claims in published maps and institutional affiliations.

\section{Received: 18 September 2018 Accepted: 18 October 2018}

Published online: 26 October 2018

\section{References}

1. Boivin J, Bunting L, Collins JA, Nygren KG. International estimates of infertility prevalence and treatment-seeking: potential need and demand for infertility medical care. Hum Reprod. 2007;22(6):1506-12.

2. Maroufizadeh S, Ghaheri A, Amini P, Samani RO. Psychometric properties of the fertility quality of life instrument in infertile Iranian women. Int J Fertil Steril. 2017;10(4):371-9.

3. Maroufizadeh S, Ghaheri A, Samani RO, Ezabadi Z. Psychometric properties of the satisfaction with life scale (SWLS) in Iranian infertile women. Int J Reprod Biomed. 2016;14(1):57-62.

4. Maroufizadeh S, Ghaheri A, Almasi-Hashiani A, Mohammadi M, Navid B, Ezabadi Z, Samani RO. The prevalence of anxiety and depression among people with infertility referring to Royan Institute in Tehran, Iran: a crosssectional questionnaire study. Middle East Fertil Soc J. 2017;23(2):103-6.

5. Omani-Samani R, Maroufizadeh S, Ghaheri A, Navid B. Generalized anxiety Disorder-7 (GAD-7) in people with infertility: a reliability and validity study. Middle East Fertil Soc J. 2018. https://doi.org/10.1016/j.mefs.2018.01.013.

6. Samadaee-Gelehkolaee K, McCarthy BW, Khalilian A, Hamzehgardeshi Z, Peyvandi S, Elyasi F, Shahidi M. Factors associated with marital satisfaction in infertile couple: a comprehensive literature review. Glob J Health Sci. 2016; 8(5):96-109.

7. Tao P, Coates R, Maycock B. Investigating marital relationship in infertility: a systematic review of quantitative studies. J Reprod Infertil. 2012;13(2):71-80.

8. Whisman MA, Uebelacker LA, Weinstock LM. Psychopathology and marital satisfaction: the importance of evaluating both partners. J Consult Clin Psychol. 2004;72(5):830-8.

9. Peterson $\mathrm{BD}$, Newton $\mathrm{CR}$, Rosen $\mathrm{KH}$. Examining congruence between partners' perceived infertility-related stress and its relationship to marital adjustment and depression in infertile couples. Fam Process. 2003;42(1):59-70.

10. Kenny DA, Kashy DA, Cook WL. Dyadic Data Analysis. New York: Guilford Press; 2006.

11. Laursen B, Little TD, Card NA. Handbook of developmental research methods. New York: Guilford Press; 2012.

12. Ackerman RA, Ledermann T, Kenny DA. Using dyadic analysis in health psychology. Eur Health Psychol. 2010;12(2):18-20.
13. Reed RG, Butler EA, Kenny DA. Dyadic models for the study of health. Soc Personal Psychol Compass. 2013;7(4):228-45.

14. Peterson BD, Sejbaek CS, Pirritano M, Schmidt L. Are severe depressive symptoms associated with infertility-related distress in individuals and their partners? Hum Reprod. 2013;29(1):76-82.

15. Donarelli Z, Kivlighan DM Jr, Allegra A, Coco GL. How do individual attachment patterns of both members of couples affect their perceived infertility stress? An actor-partner interdependence analysis. Pers Individ Dif. 2016;92:63-8.

16. Moura-Ramos M, Santos TA, Canavarro M. The role of attachment anxiety and attachment avoidance on the psychosocial well-being of infertile couples. J Clin Psychol Med Settings. 2017;24(2):132-43.

17. Maroufizadeh S, Hosseini M, Foroushani AR, Omani-Samani R, Amini P. The effect of depression on quality of life in infertile couples: an actor-partner interdependence model approach. Health Qual Life Outcomes. 2018;16(1):73.

18. Pasch LA, Sullivan KT. Stress and coping in couples facing infertility. Curr Opin Psychol. 2017;13:131-5.

19. Maroufizadeh S, Hosseini M, Foroushani AR, Omani-Samani R, Amini P. The relationship between marital satisfaction and depression in infertile couples: an actor-partner interdependence model approach. BMC Psychiatry. 2018:18(1):310

20. Zegers-Hochschild F, Adamson GD, de Mouzon J, Ishihara O, Mansour R, Nygren K, Sullivan E, Van der Poel S, Technology ICfMAR, Organization WH. The international committee for monitoring assisted reproductive technology (ICMART) and the world health organization (WHO) revised glossary on ART terminology, 2009. Fertil Steril. 2009;92(5):1520-4.

21. Fowers BJ, Olson DH. ENRICH marital satisfaction scale: a brief research and clinical tool. J Fam Psychol. 1993;7(2):176-85.

22. Zigmond AS, Snaith RP. The hospital anxiety and depression scale. Acta Psychiatr Scand. 1983;67(6):361-70.

23. Amini P, Maroufizadeh S, Omani Samani R. Evaluating the factor structure, item analyses, and internal consistency of hospital anxiety and depression scale in Iranian infertile patients. Int J Reprod Biomed. 2017;15(5):287-96.

24. Hong S, Kim S. Comparisons of multilevel modeling and structural equation modeling approaches to actor-partner interdependence model. Psychol Rep. 2018. https://doi.org/10.1177/0033294118766608.

25. Salazar LR. The negative reciprocity process in marital relationships: a literature review. Aggress Violent Behav. 2015;24:113-9.

26. Wang J-Y, Hsieh M-H, Lin P-C, Liu C-S, Chen J-D. Parallel contagion phenomenon of concordant mental disorders among married couples: a nationwide cohort study. J Epidemiol Community Health. 2017;71:640-7. https://doi.org/10.1136/jech-2016-208283.

27. Card NA, Selig JP, Little T. Modeling dyadic and interdependent data in the developmental and behavioral sciences. New York: Routledge; 2011.

28. Ledermann T, Kenny DA. The common fate model for dyadic data: variations of a theoretically important but underutilized model. J Fam Psychol. 2012;26(1):140-8.

29. Reis HT, Sprecher S. Encyclopedia of human relationships, vol. 1. New York: Sage; 2009.

30. Ledermann T, Macho S. Mediation in dyadic data at the level of the dyads: a structural equation modeling approach. J Fam Psychol. 2009;23(5):661-70.

31. Galovan AM, Holmes EK, Proulx CM. Theoretical and methodological issues in relationship research: considering the common fate model. J Soc Pers Relat. 2017;34(1):44-68.

32. Woody E, Sadler P. Structural equation models for interchangeable dyads: being the same makes a difference. Psychol Methods. 2005;10(2):139-58.

33. Bentler PM. Comparative fit indexes in structural models. Psychol Bull. 1990; 107(2):238-46.

34. Byrne BM. Structural equation modeling with EQS and EQS/windows: basic concepts, applications, and programming. Thousand Oaks: Sage Publications; 1994

35. McDonald RP, Ho M-HR. Principles and practice in reporting structural equation analyses. Psychol Methods. 2002;7(1):64-82.

36. Kline RB. Principles and practice of structural equation modeling. New York: Guilford Publications; 2015.

37. lida M, Seidman G, Shrout PE. Models of interdependent individuals versus dyadic processes in relationship research. J Soc Pers Relat. 2018;35(1):59-88.

38. Maroufizadeh S, Karimi E, Vesali S, Omani Samani R. Anxiety and depression after failure of assisted reproductive treatment among patients experiencing infertility. Int J Gynecol Obstet. 2015;130(3):253-6.

39. Omani-Samani R, Ghaheri A, Navid B, Sepidarkish M, Maroufizadeh S. Prevalence of generalized anxiety disorder and its related factors among infertile patients in Iran: a cross-sectional study. Health Qual Life Outcomes. 2018;16(1):129. 
40. Peterson BD, Newton CR, Rosen KH, Skaggs G. Gender differences in how men and women who are referred for IVF cope with infertility stress. Hum Reprod. 2006;21(9):2443-9.

41. Omani-Samani R, Maroufizadeh S, Ghaheri A, Amini P, Navid B. Reliability and validity of the Kansas marital satisfaction scale (KMSS) in infertile people. Middle East Fertil Soc J. 2017;23(2):154-7.

42. Maroufizadeh S, Omani-Samani R, Almasi-Hashiani A, Navid B, Sobati B, Amini P. The relationship assessment scale (RAS) in infertile patients: a reliability and validity study. Middle East Fertil Soc J. 2018. https://doi.org/10. 1016/j.mefs.2018.04.001.

43. Donarelli Z, Lo Coco G, Gullo S, Salerno L, Marino A, Sammartano F, Allegra A. The fertility quality of life questionnaire (FertiQoL) relational subscale: psychometric properties and discriminant validity across gender. Hum Reprod. 2016;31(9):2061-71.

44. Huppelschoten AG, Van Dongen A, Verhaak C, Smeenk J, Kremer J, Nelen $W$. Differences in quality of life and emotional status between infertile women and their partners. Hum Reprod. 2013;28(8):2168-76.

45. Drosdzol A, Skrzypulec V. Evaluation of marital and sexual interactions of polish infertile couples. J Sex Med. 2009;6(12):3335-46.

Ready to submit your research? Choose BMC and benefit from:

- fast, convenient online submission

- thorough peer review by experienced researchers in your field

- rapid publication on acceptance

- support for research data, including large and complex data types

- gold Open Access which fosters wider collaboration and increased citations

- maximum visibility for your research: over $100 \mathrm{M}$ website views per year

At $\mathrm{BMC}$, research is always in progress.

Learn more biomedcentral.com/submissions 